\title{
Evaluation of germination ability of cotton cultivars (Gossypium hirsutum L.) under artificial stress conditions
}

\author{
Eleni TSALIKI ${ }^{1 *}$, Fotios XANTHOPOULOS ${ }^{2}$, Urania KECHAGIA ${ }^{3}$ and Christos LELOUDIS ${ }^{1}$ \\ ${ }^{1}$ Hellenic Agricultural Organization - DEMETER, Plant Breeding and Genetic Resources Institute, 57001 Thermi, \\ Thessaloniki, Greece. \\ ${ }^{2}$ Cotton Breeding Consultant, Chimonidou 55133 Kalamaria, Thessaloniki, Greece. \\ ${ }^{3}$ Scientific Consultant, Chimonidou 55133 Kalamaria, Thessaloniki, Greece.
}

${ }^{*}$ Corresponding author. Email: tsaliki@ipgrb.gr

Copyright (C) 2019 Agubosi et al. This article remains permanently open access under the terms of the Creative Commons Attribution License 4.0, which permits unrestricted use, distribution, and reproduction in any medium, provided the original work is properly cited.

Received 11th December, 2018; Accepted 22nd January, 2019

\begin{abstract}
The present study aimed to evaluate the resistance in water stress conditions of the cultivated varieties in Greece, taking into consideration not only the economic importance of cotton worldwide and especially in Greece, where almost $10 \%$ of the agriculture land was cotton cultivated, but also the importance of the factors which interfere in its seed germination. Eleven cotton cultivars were evaluated for germination efficiency concerning both, the relevant percentage and the germination rates. Seeds from selected varieties cultivated in Greece, were placed for seven days, in conditions of increased osmotic pressure achieved by gradually increasing concentrations of polyethylene-glycol solutions. A differentiation in cultivars behavior concerning the percentage and the germination rate was observed. Among the eleven cultivars tested "Hermes" was the least and "Sandra" was the most affected concerning the two measured parameters. The remaining cultivars are graded in intermediate order. In all cases the cultivar $\times$ polyethylene-glycol interaction was significant.
\end{abstract}

Keywords: Artificial stress, cotton, germination ability, germination rate.

\section{INTRODUCTION}

Cotton plant has the most complex structure of any major field crop while the germination and seedling establishment is one of the most critical stage for plant development. One of the major abiotic stresses affecting plant productivity is water stress resulting through drought in anatomical and morphological alterations as well as changes in physiological and biochemical processes affecting functions of the plants (Megha and Mummigatti, 2017)

The cotton varieties differ in their levels of resistance to adverse environmental conditions, namely in germination under dry and hot conditions. The selection of appropriate genotypes that are better adapted to water stress conditions, based on genetic variability, is the most effective and the most economical way to improve cotton (Wayne and Cothren, 1999).
Germinating seeds are particularly prone to chilling injury due to early planting dates and in addition to this, water stress, oxygen deficiency and soil compaction may result in reduced germination rates and poor quality seedlings (Megha and Mummigatti, 2017). The sharp temperature increasing causes soil compaction and as a result delays and even results in the failure of germination. Under these circumstances the watering is unavoidable which may increase cultivation cost (Hake et al., 1996).

Cotton (Gossypium spp.) "the white gold" is one of the most important crops of Greece, playing a significant role in Greek agriculture sector and industrial economy of country, giving income to more than 55,000 farmers and the same number of people in production, processing, trading and transportation. Early sowing and use of cotton varieties resistance to drought is of great importance for 
countries like Greece, because it is in the margins of cotton belt with usually cool temperatures and high moisture at planting time.

Polyethylene-glycol (PEG) has been used worldwide, in order to estimate the resistance of various seeds to germinate under drought laboratory conditions (Hadas, 1977). PEG when dissolved in water prevents the nutrients intake of the plants. The denser is a solution, the greater negative pressure needed for the plant to absorb water and the laboratory results of germination rates of many species (Ashraf and Abu-Shakra, 1978; Kumar et al., 2017, Abido and Zsombik, 2018) using PEG solutions confirmed that there is a very close relationship with the results in the field.

Somers et al. (1983) also used PEG, in order to create drought conditions in the laboratory and select genotypes of sunflower that grows best under dry and hot conditions. In solutions of 20 to $40 \mathrm{~g} \mathrm{PEG}$ molecular weight 20000/100 $\mathrm{ml} \mathrm{H}_{2} \mathrm{O}$, which created environment from - 6 to -21 bars, the same researchers found wide variation in the percentage germination. Their results were subsequently confirmed in the field.

The aim of this study was to evaluate the germination efficiency concerning both, the relevant percentage and the germination rates of eleven cotton varieties cultivated in Greece, with the use of different concentrations of PEG solutions.

\section{MATERIALS AND METHODS}

The laboratory experiments took place in former Cotton and Industrial Plant Institute of Hellenic Agricultural Organization - DEMETER with cotton seeds of eleven commercial varieties, registered to Greek National Catalogue. The commercial names of cotton varieties are Bolina, Carmen, Celia, Elina, Ethiage-1, Hermes, Midas, Nova, Opal, Sandra and Volcano and the criterion used for the varieties selection was their area cultivation percentage in Greece.

One hundred seeds from each variety, divided in two, in order for the experimental error to be smaller and the comparison more accurate (Steel and Torrie 1980). The seeds plated in petris, with $10 \mathrm{ml}$ of PEG molecular weight 6000 (Sigma-Aldrich). The concentrations of PEG used were $0,40,80,120,160 \mathrm{~g} / 100 \mathrm{ml} \mathrm{H} \mathrm{H}_{2}$. The petris were placed covered in growth chambers (CDR SG - 500 E) at $28^{\circ} \mathrm{C}$ for seven days, in order to avoid impact of environment moisture.

The experimental design used was the complete randomised $(\mathrm{CR})$ with split splot arrangement. Within each repetition randomized levels of the first factor $A$ (solution PEG 0, 40, 80, 120, $160 \mathrm{~g} / 100 \mathrm{ml} \mathrm{H} 2 \mathrm{O}$ ) used and subsequently at each level was the randomization of levels of the second factor $B$ (11 varieties).

Germination percentage measurements were made every day the same time and a seed with a radicle $>0.5$ $\mathrm{cm}$ was considered germinated. In each repetition there was a blank treatment. The germination rate measured by the type $(\mathrm{Ve}=\mathrm{Snx} / \mathrm{dx})$ proposed by Camargo and Vaughan (1973) for sorghum. In this equation $n x$ is the number of seeds germinated on day $x$ and $d x$ the number of days from the beginning of germination till $x$ days. Data obtained were analyzed for significance by testing the difference of means LSD $(P=0.05)$.

\section{RESULTS AND DISCUSSION}

Abiotic stresses cause a wide range of morphophysiological and biochemical changes that adversely affect cotton growth and productivity. In general, abiotic stress severely restrict cotton growth and development, such as reducing plant height, fresh and dry weights of shoots and roots, leaf area index, node number, photosynthesis, transpiration rate, stomatal conductance, yield, fiber quality, and canopy and root development (Loka et al., 2011). More specific drought has a negative effect on all cotton growth stages; however, seedling, flowering and boll development stages are most sensitive to water deficit (Abdelraheem et al., 2019).

Table 1 shows the results from the statistical analysis of variance of the percentage germination and germination rate of eleven cotton varieties. The effect of PEG is statistical significant both for the germination percentage and for the germination rate. The varieties had statistically significant differences for both these measurements. The interaction between varieties and PEG was also significant, and all varieties did not react in the same way in the increased osmotic pressure environments, as also reported from Megha and Mummigatti (2017) for Indian cotton genotypes.

Table 2 presents the mean values of germinated cotton seeds in different PEG solutions. Examining the external means $(A)$, with $L_{S D}=5.02$ (between two averages $A$ ), it was observed that the differences were significant among all treatments. The general mean value of blank percentage germination in all varieties was $83.7 \%$, significantly higher than the corresponding mean value of the seeds germinated in $40 \mathrm{~g} \mathrm{PEG} / 100 \mathrm{ml} \mathrm{H} \mathrm{H}_{2} \mathrm{O}$ solution. In $80 \mathrm{~g} \mathrm{PEG} \mathrm{/} 100 \mathrm{ml} \mathrm{H} 2 \mathrm{O}$ solution, the mean value of all varieties reduced to $57.6 \%$ while in $120 \mathrm{~g} \mathrm{PEG} / 100 \mathrm{ml}$ $\mathrm{H}_{2} \mathrm{O}$ solution the germination percentage was $30.2 \%$ and only $2.2 \%$ in $160 \mathrm{~g} \mathrm{PEG} / 100 \mathrm{ml} \mathrm{H}_{2} \mathrm{O}$ solution. The negative effect in germination percentage is directly related to the concentration of PEG and this is in agreement with results obtained by Smith et al. (1989) and reported recently by Meneses et al. (2011) while there was no clear relationship between the size of the seed and its physiological performance (Meneses et al., 2018).

Examining the external means (B), with $\mathrm{LSD}_{0.5}=4.22$ (between two averages $B$ ), it was observed that variety Hermes had the higher germination percentage in all concentrations. Varieties Bolina, Carmen, Celia and 
Table 1. Analysis of variance of germination percentage and rate of cotton seeds indifferent polyethylene glycol (PEG) solutions.

\begin{tabular}{lccccc}
\hline $\begin{array}{l}\text { Sources of } \\
\text { variance }\end{array}$ & $\begin{array}{c}\text { Degrees of } \\
\text { Freedom }\end{array}$ & \multicolumn{2}{c}{ Mean Square Germination } & \multicolumn{2}{c}{ F Germination } \\
\cline { 2 - 6 } & 4 & Percentage & Rate & Percentage & Rate \\
\hline PEG (A) & 15 & 11611.7 & 2306.3 & & $* *$ \\
Error A & 10 & 30.5 & 7.6 & & \\
Varieties (B) & 40 & 755.7 & 97.5 & $* *$ & $* *$ \\
Interaction & 150 & 11.4 & 10.5 & $* *$ & $* *$ \\
Error A & 219 & & 2.8 & & \\
Total & & & & & \\
\hline
\end{tabular}

${ }^{* *} \mathrm{P}<0.01$.

Table 2. Percentage of germination (mean values) of cotton seeds in different polyethylene glycol (PEG) solutions.

\begin{tabular}{lcccccc}
\hline \multirow{2}{*}{ Varieties (B) } & \multicolumn{7}{c}{$\mathbf{g}$ of PEG / $\mathbf{1 0 0} \mathbf{~} \mathbf{~ I ~} \mathbf{H}_{\mathbf{2}} \mathbf{O}(\mathbf{A})$} & \multirow{2}{*}{ Average } \\
\cline { 2 - 6 } & $\mathbf{0}$ & $\mathbf{4 0}$ & $\mathbf{8 0}$ & $\mathbf{1 2 0}$ & $\mathbf{1 6 0}$ & \\
\hline Celia & 84.0 & 79.0 & 66.5 & 42.5 & 3.0 & 55.0 \\
Bolina & 85.0 & 78.5 & 70.5 & 43.0 & 3.5 & 56.1 \\
Hermes & 83.0 & 85.5 & 81.0 & 57.0 & 1.0 & 61.5 \\
Nova & 84.0 & 61.5 & 38.5 & 7.0 & 2.0 & 38.6 \\
Opal & 84.0 & 68.0 & 49.5 & 26.0 & 5.5 & 46.6 \\
Elina & 83.0 & 71.5 & 61.0 & 28.5 & 5.0 & 49.8 \\
Carmen & 84.0 & 77.5 & 69.5 & 46.5 & 0.5 & 55.6 \\
Ethiage-1 & 83.0 & 45.5 & 49.5 & 24.0 & 1.0 & 40.6 \\
Volcano & 83.0 & 81.0 & 66.0 & 33.0 & 2.0 & 53.0 \\
Sandra & 84.0 & 45.0 & 37.5 & 13.5 & 1.0 & 36.2 \\
Midas & 84.0 & 66.5 & 44.0 & 11.0 & 0.0 & 41.1 \\
Average & 83.7 & 69.0 & 57.6 & 30.2 & 2.2 & \\
\hline
\end{tabular}

LSD 0.5; 5.02 between two A averages; 4.22 between two $B$ averages; 9.44 between two $B$ averages in the same A level; 10.31 between two A averages in the same or different $B$ level.

Volcano had high germination percentage with no statistical significant differences while Midas, Ethiage-1 and Nova presented the lower percentage with the lowest percentage in Sandra variety. These results shown that drought conditions caused by PEG, reduced the germination ability of all tested varieties with statistical significant differences between them.

PEG concentrations of $120 \mathrm{~g}$ and $160 \mathrm{~g} / 100 \mathrm{ml} \mathrm{H} \mathrm{H} \mathrm{O}$ reduced the germination ability with no practical interest in the field. On the other hand, the conditions of $40 \mathrm{~g} / 100 \mathrm{ml}$ $\mathrm{H}_{2} \mathrm{O}$ and $80 \mathrm{~g} \mathrm{PEG} / 100 \mathrm{ml} \mathrm{H} \mathrm{H}_{2} \mathrm{O}$ more simulated with the field conditions.

In the concentration of $40 \mathrm{~g} \mathrm{PEG} / 100 \mathrm{ml} \mathrm{H}_{2} \mathrm{O}$ observed great variety differentiation and varieties Hermes, Volcano, Celia, Bolina and Carmen show high percentage germination with no significant differences $\left(\mathrm{LSD}_{05}=9,44\right.$ between two $B$ averages in the same $A$ level). The comparison of the mean values of the above varieties with the values of control $\left(\mathrm{LSD}_{05}=10.31\right.$ between two $\mathrm{A}$ averages in the same B level) shown no statistical significant differences. This means that low levels of drought have no effect on these varieties. On the other hand, the germination percentage of varieties Nova, Opal, Elina, Ethiage-1, Sandra and Midas observed statistically differences in comparison with the control. This means that the lack of moisture at levels similar to $40 \mathrm{~g}$ PEG / $100 \mathrm{ml}$ $\mathrm{H}_{2} \mathrm{O}$ has no effect to the first group of varieties but to the second group of above referred varieties a water deficit at emergence stage will affect the seed germination and maybe result in a need for replanting to the field.

To the next concentration level of $80 \mathrm{~g} \mathrm{PEG} / 100 \mathrm{ml} \mathrm{H} \mathrm{H}_{2} \mathrm{O}$ observed a statistical significant differentiation between the varieties. Germination percentage of Hermes variety was $81 \%$, non-statistically different both from the prior concentration and from the control. Instead of this, Sandra variety has only $37.5 \%$ germination statistical lower from the other varieties, except Midas and Nova.

The $120 \mathrm{~g} \mathrm{PEG} / 100 \mathrm{ml} \mathrm{H} \mathrm{H}_{2} \mathrm{O}$ concentration resulted in the germination decrease and in some varieties at the level of zero. Hermes variety germinated to the higher observed 
Table 3. Mean values of germination rates of cotton seeds in different polyethylene glycol (PEG) solutions.

\begin{tabular}{lcccccc}
\hline \multirow{2}{*}{ Varieties (B) } & \multicolumn{7}{c}{$\mathbf{g}$ of PEG / $\mathbf{1 0 0} \mathbf{~} \mathbf{~} \mathbf{H}_{\mathbf{2}} \mathbf{O}(\mathbf{A})$} & \multirow{2}{*}{ Average } \\
\cline { 2 - 6 } & $\mathbf{0}$ & $\mathbf{4 0}$ & $\mathbf{8 0}$ & $\mathbf{1 2 0}$ & $\mathbf{1 6 0}$ & \\
\hline Celia & 18.1 & 16.8 & 12.3 & 5.9 & 0.3 & 10.7 \\
Bolina & 19.2 & 16.4 & 11.9 & 4.7 & 0.3 & 10.5 \\
Hermes & 22.8 & 22.2 & 17.1 & 10.4 & 0.2 & 14.5 \\
Nova & 14.3 & 13.2 & 7.9 & 1.2 & 0.5 & 7.4 \\
Opal & 13.4 & 14.6 & 10.0 & 3.5 & 0.7 & 8.4 \\
Elina & 18.9 & 17.5 & 14.1 & 6.3 & 0.8 & 11.5 \\
Carmen & 19.2 & 17.6 & 14.4 & 7.5 & 0.1 & 8.0 \\
Ethiage-1 & 14.0 & 10.1 & 10.9 & 4.8 & 0.1 & 8.0 \\
Volcano & 19.9 & 17.3 & 11.5 & 5.2 & 0.2 & 10.8 \\
Sandra & 13.7 & 10.8 & 8.9 & 2.3 & 0.2 & 7.2 \\
Midas & 18.1 & 15.5 & 10.5 & 2.7 & 0.0 & 9.3 \\
Average & 17.4 & 15.6 & 11.8 & 5.0 & 0.3 & \\
\hline
\end{tabular}

LSD $0.5 ; 1.25$ between two A averages; 1.05 between two $B$ averages; 2.34 between two $B$ averages in the same A level; 2.41 between two A averages in the same or different B level.

level of $57 \%$ and Nova variety to the lower level of $7 \%$.

Finally with $160 \mathrm{~g} \mathrm{PEG} / 100 \mathrm{ml} \mathrm{H} \mathrm{H}_{2} \mathrm{O}$ the germination percentages of all varieties show no statistical differences between them.

In general, a differentiation in cultivars behavior concerning the germination percentage was observed and the negative effect was directly related to the concentration of PEG. Babu et al. (2014) stated that the maximum level of PEG 6000 concentration for cotton seed germination was $25 \%(-0.735 \mathrm{MPa})$, above this concentration the seed germination was inhibited in all the twelve tested Indian genotypes while Zhang et al., (2007) proposed to handle drought tolerance evaluation of cotton with PEG waterstress at real-leaf stage.

Table 3 presents the mean values of germination rates of seeds in PEG solutions. The examination of external mean values $(A)$ with $\mathrm{LSD}_{05}=1.25$ (between two $A$ averages) shows that the germination rate reduced statistically significant as long as the concentration of PEG increase. The control mean value germination rate was 17.4, in $40 \mathrm{~g} \mathrm{PEG} / 100 \mathrm{ml} \mathrm{H} 2 \mathrm{O}$ was 15.6 and to the $160 \mathrm{~g}$ PEG / $100 \mathrm{ml} \mathrm{H}_{2} \mathrm{O}$ was 0.3 .

The external mean values with $\mathrm{LSD}_{05}=1.05$ (between two B averages) shows that Hermes variety grew with higher rate in comparison with the others and this was followed by varieties Carmen, Elina, Volcano and Celia.

The comparison of mean values in the same PEG level has more practical interest because Hermes variety germinated faster, Volcano, Bolina, Carmen, Elina, Celia and Midas with an intermediate rate and the lower germination rate was observed in varieties Nova, Ethiage1, Sandra and Opal.

$40 \mathrm{~g} \mathrm{PEG} / 100 \mathrm{ml} \mathrm{H}_{2} \mathrm{O}$ concentration has no effect on Hermes variety and varieties Sandra and Ethiage-1 showed the lower rates. Also, to the concentration of $80 \mathrm{~g}$
PEG / $100 \mathrm{ml} \mathrm{H} \mathrm{H}_{2} \mathrm{O}$, Hermes variety has the higher germination rate.

In conclusion, germination ability of Greek cotton varieties reduced under artificial stress conditions with the use of PEG. The negative effect is directly related to the concentration of PEG while in all cases the cultivar $x$ polyethylene-glycol interaction was significant. A differentiation in cultivars behavior concerning the percentage and the germination rate was also observed and among the eleven cultivars tested "Hermes", was the least and "Sandra", was the most affected concerning the two measured parameters.

\section{CONFLICT OF INTEREST}

The authors declare that they have no conflict of interest.

\section{REFERENCES}

Abdelraheem, A., Esmaeili, N., O'Connell, M., \& Zhang, J. (2019). Progress and perspective on drought and salt stress tolerance in cotton. Industrial Crops and Products, 130, 118129.

Abido, W. A. E., \& Zsombik, A. L. (2018). Effect of water stress on germination of some Hungarian wheat landraces varieties. Acta Ecologica Sinica, 38(6), 422-428.

Ashraf, C. M., \& Abu-Shakra, S. (1978). Wheat seed germination under low temperature and moisture stress. Agronomy Journal, 70(1), 135-139.

Babu, A. G., Patil, B. C., \&Pawar K. N. (2014). Evaluation of cotton genotypes for drought tolerance using PEG-6000 water stress by slanting glass plate technique. The Bioscan, 9(2), 1419-1424.

Camargo, C. P., \& Vaughan, C. E. (1973, January). Effect of seed vigor on field performance and yield of grain sorghum 
(Sorghum bicolor (L) Moench). In Proceedings of the Association of Official Seed Analysts, 63, 135-147.

Hadas, A. (1977). A simple laboratory approach to test and estimate seed germination performance under field conditions. Agronomy Journal, 69(4), 582-588.

Hake, S. J., Kerby, T. A., \& Hake, K. D. (1996). Cotton production manual. Publication 3352. Oakland, California: Division of Agriculture and Natural Resources.

Kumar, P. A., Reddy N. N., \& Lakshmi, N. J. (2017). PEG induced screening for drought tolerance in tomato genotypes. International Journal of Current Microbiology and Applied Sciences, 6(7), 168-181.

Loka, D. A., Oosterhuis, D. M., \& Ritchie, G. L. (2011). Stress physiology in cotton. National Cotton Council of America.

Megha, B. R., \& Mummigatti, U. V. (2017). Evaluation of Hirsutum cotton genotypes for drought tolerance under different osmotic potential and filed capacities. International Journal of Bioresource and Stress Management, 8(2), 299-308.

Meneses, C. H. S. G., Bruno, R. L. A., Pedro, D. F., Pereira, W. E., Lima, L. H. G. M., Lima, M. M. A, \& Vidal, M. S. (2011). Germination of cotton cultivar seeds under water stress induced by polyethyleneglycol-6000. Science Agriculture, 68(2), 131-138.
Meneses, C. H. S. G., Bruno, R. L. A., Pedro, D. F., Pereira, W. E., Lima, L. H. G. M., Lima, M. M. A., \& Vidal, M. S. (2018). Seed size and physiological quality of three cultivars of cotton. Científic@ - Multidisciplinary Journal, 5(2) 127-131.

Smith, R. L., Hoveland, C. S., \& Hanna W. W. (1989). Water stress and temperature in relation to seed germination of pearl millet and sorghum. Agronomy Journal, 81: 303-305.

Somers, D. A., Ullrich, S. E., \& Ramsay, M. F. (1983). Sunflower germination under simulated drought stress. Agronomy Journal, 75(3), 570-572.

Steel, G. D., \& Torrie, J. H. (1980). Principles and Procedures of Statistics. New York, USA: MacGraw Hill Company.

Wayne, C. S., \& Cothren, J, T. (1999). Cotton Origin History Technology and Production. New York, USA: John Wiley \& Sons, Inc.

Zhang, X., Liu, C., Wang J, Li F., \& Ye, W. (2007). Droughttolerance evaluation of cotton with PEG water-stress method. Cotton Science, 19(3), 205-209. 